\section{RECENT ADVANCES IN TRACHOMA*}

BY

F. H. STEWART, M.D., D.Sc.

MAJOR I.M.S. (RET.) ; PATHOLOGIST, MEMORIAL OPHTHALMIC LABORATORY, GIZA, EGYPT

Trachoma is a disease affecting infants, children, and adults ; it frequently destroys or impairs sight, is painful and troublesome, and greatly reduces individual efficiency. It is distributed round the whole tropical and subtropical zones, with extensions into temperate climates. The proportion of the population affected may be as high as 90 to 99 per cent. It is probably no exaggeration to say that one-quarter of the population of the globe suffers from it. The discovery of the cause of this disease is therefore one of the prizes of scientific medicine.

\section{Theories of Causaticn}

In spite of more than fifty years of work this question is still undetermined. The difficulties in the way are considerable. Until recently no animal was known which was uniformly susceptible; the ordinary laboratory animals such as rabbits, guinea-pigs, dogs, etc., are immune, and the more common monkeys are quite unreliable. Bacterioscopic methods reveal no organism constantly present, nor has any one been cultured which reproduces the disease. Filtrates are generally not infective. There are, however, two important theories of origin: (1) from bacteria, and (2) from a granular virus.

1. In 1925 Noguchi isolated a bacillus which he named $B$. granulosis from trachoma in North American Indians. $\mathrm{He}$ claimed that it produced characteristic and progressive lesions in chimpanzees and rhesus monkeys. This organism has not, however, been constantly found by other investigators. It cannot be isolated from the highly infectious conjunctival secretion, and inoculation into man does not cause trachoma. It has therefore not been generally accepted.

2. The Prowazek-Halberstaedter body, an inclusion in epithelial cells of trachomatous conjunctivae, was discovered by these two workers in Java in the year 1906 . In its fully developed state it consists of a vacuole filled by a vast number of granules, the elementary granules, each about $1 / 4 \mu$ in diameter. The early stages of this inclusion are called initial bodies. They may be free or intracellular. The former, as described by Lindner, cannot be distinguished morphologically from polar staining bacilli such as Pasteurella avicida. The latter take various shapes resembling bacteria, such as cocci, bacilli, etc. The staining reactions of trachoma films to Giemsa are instructive. The following stain dark blue -namely, all bacteria and all " initial bodies," both free and intracellular-while elementary granules stain purple. The inclusion can be demonstrated in a varying percentage of trachoma cases, different authors claiming from 40 to 100 per cent. The elementary granules when not aggregated together have no distinguishing characteristics (Halberstaedter), and may be present without being demonstrable. They cannot be cultivated. When material from a conjunctiva with inclusions is transferred to another eye, either of man or monkey, inclusions may form in the second eye. In man these transferred inclusions are preceded by a vast number of " initial bodies" identical in appearance with staphylococci or streptococci (Mijashita, three cases), or by an acute Koch-Weeks conjunctivit:s (Thygeson, one case) or an acute conjunctivitis of undetermined nature (Addario, three cases ; Greeff, one case ; Micael and Vancea, eight

* A paper read to the Egyptian Branch of the British Medical Association at Cairo, April 25th, 1935. cases; Kapuscinski seven cases). These human cases developed typ:cal trachoma. Of inoculated monkeys only one in four develops inclusions, which may be accompanied by clinical trachoma, but more often are not, while clinical trachoma may appear without inclusions. Filtration experiments have been negative except in three cases.

\section{Laboratory Work at Giza}

We now turn to the work which has been done in this laboratory during the last five years.

1. In the first place, an animal had to be found which would be constantly susceptible. The Barbary apes, recommended by the Pasteur Institute of Tunis, proved completely resistant to Egyptian trachoma, but baboons both grey and yellow, and grivets, from the Sudan, were found to react in every case. Experimental trachoma in these animals consists of an outbreak of follicles covering the whole upper retrotarsal conjunctiva, appearing twenty to thirty days after inoculation and persisting for long periods.

2. Examination of conjunctival films in three hundred cases. Prowazek-Halberstaedter bodies were not found in pure, uncomplicated trachoma, but only in trachoma complicated by infection with bacter:a, especially the Koch-Weeks bacillus and the gonococcus.

3. "Initial bodies " in these cases are bacteria phagocytosed by epithelial cells. As the bacteria are digested elementary granules appear in their place.

4. In infected monkeys, inclusions have been found only in two out of twenty-six experiments, and then in very small numbers. Free elementary granules sufficiently numerous to be identified have been found only in four out of twenty-six. Monkeys' eyes are relatively free from pathogenic germs, and of course never harbour Koch-Weeks bacilli or gonococci, although acute conjunctivitis for twenty-four to forty-eight hours follows inoculation of these germs.

5. After passing suspensions of virulent trachoma secretion through Berkefeld $\mathrm{V}$ candles or gradocol membranes of 0.6 and $0.7 \mu$ a.p.d., the filtrate is not infective, although it may contain elementary granules.

\section{Examination of Hypothesis}

We are therefore led to the hypothesis that the granular virus of trachoma is introduced into the conjunctiva in the bodies of bacteria of several species, the Koch-Weeks bacillus and gonococcus being the most important in Egypt. These bacteria, acting as intermediate hosts, are phagocytosed to form the Prowazek-Halberstaedter bodies, which are the ports of entry for the elementary granules of the virus. The latter are liberated by the bursting of the inclusions, and are dispersed through the conjunctiva. They are then no longer recognizable.

Looking for confirmation of this hypothesis in the literature we recall the initial bodies, mentioned above, which in Central Europe (Lindner and Botteri) and in North America cannot be distinguished while free from the bacillus Pasteurella. In Japan (Mijashita), in the Malay Islands (Prowazek and Halberstaedter), and in Europe intracellular forms have all the appearance of staphylococci, streptococci, pneumococci, and gonococci, or again of Pasteurella. In New York inclusions are formed from Koch-Weeks and other haemophilic bacilli (Williams).

We also find that similar inclusions occur in: (1) inclusion blennorrhoea of the newborn; (2) swimming-bath conjunctivitis; (3) epitheliosis desquamativa of Samoa ; (4) chronic papillary hypertrophy of the Mariannes ; (5) the conjunctivitis of swine fever. Taking these in order, (1) is associated with the gonococcus to this extent, that mixed cases containing gonococci and inclusions occur out of all proportion to the mathematical probability of 
two unrelated things coinciding; they would coincide more frequently still if it were not for the Credé prophylactic which destroys gonococci but not inclusions, since the mothers of children with pure inclusion blennorrhoea have repeatedly been found carrying gonococci. Inclusion blennorrhoea can, however, be reproduced from a filtrate (Botteri) ; it is therefore probable that, being a more acute disease than trachoma, it can be transmitted directly in experiments as well as by an intermediate bacterial host. (2) in some outbreaks has been associated with Koch-Weeks bacilli. It is probably the adult form of (1), the two together making up paratrachoma of Lindner. (3) is definitely associated with the Diplococcus samoensis of Rossiter. (4) is associated with Bacillus marianensis, while nothing is known of the bacteriology of (5).

\section{Conclusion}

Summing up, then, this hypothesis explains the resemblance between initial bodies and bacteria, the sudden transition from the former to the very different elementary granules, the fact that inclusions are found only in complicated trachoma, their rarity in the relatively aseptic conjunctivae of monkeys, the clinical observation that trachoma follows acute Koch-Weeks ophthalmia in Egyptian villagers (Wilson), the non-filterability of the disease and its lack of resistance to glycerin.

This hypothesis is at present being treated by experiment. If it is not true, there seem to be two further alternatives. One is that the elementary granules are unable to pass a filter in an infective condition. They are described by Halberstaedter and others as surrounded by a clear space in Giemsa preparations, which may represent a capsule. A capsule would double or treble their size, and would almost certainly render them unfilterable, while it is possible that non-capsulated forms are not infective. The other alternative is that the elementary granules play no part in the causation of trachoma.

\section{BIBLIOGRAPHY}

Addario: Arch. Augenheilk., 1900, xli, 20

Botteri: Klin. Mon. Augenheilk. 1912, 1, 653

Greeff, Frosch, and Clausen: Arch. Augenheilk., 1907, 1viii, 52

Halberstaedter and Prowazek: Arb. gesundheitsamt, Berlin, 1907, xxvi, 44.

Halberstaedter: Handb. d. Pathogenen Protozoen, 1911, p. 172

Kapuscinski: Proc. Warsaw Akad. Med. Sci., 1921.

Lindner: $v$. Graefe's Arch., 1910, lxxvi, 559.

Micael and Vancea: Rev. Inter. Trach., 1932, p. 33.

Mijashita: Klin. Mon. Augenheilk., 1918, xlvi, II, 626.

Noguchi: Journ. Exper. Med., 1928, xlvii, Supp. 2.

Rossiter: U.S. Naval Med. Bull., 1908, 1909, II and III.

Stewart: Annual Report Giza Mem. Oph. Lab. for 1933, 1934.

Thygeson: Amer. Journ. Oph., 1933, xvi, 409.

Williams, A. Wessels: Journ. Infect. Dis., 1914, xiv, 261.

Wilson: Annual Report Giza Med. Oph. Lab. for 1930, 1931, p. 63.

E. Fischmann (Thèse de Paris, 1935, No. 131) states that during the Middle Ages and up to the eighteenth century the Jews appear to have paid a heavy tribute to tuberculosis, but since the beginning of the nineteenth century it is generally agreed that the resistance of Jews to pulmonary tubercuiosis is much greater and the mortality much less than that of the surrounding population. Acute forms of tuberculosis are extremely rare among the Jews, the disease, when it occurs, showing a tendency to chronicity, and thereby enabling the individual to lead an almost normal life. The resistance of the Jews to tuberculosis, though it varies to a certain extent with social conditions, cannot be explained by the factor of race, as all anthropologists are agreed as to the complete absence of any racial unity among the Jews. The author thinks that the prolonged contact of past generations with tuberculous infection due to their exclusively urban existence is a better explanation of their resistance to the disease than the other causes sometimes invoked, such as hygienic or religious regulations and natural sobriety.

\section{FIVE HUNDRED FOREIGN BODIES IN THE STOMACH}

\section{R. STEWART KENNEDY, M.B., СH.B., D.P.M.}

SENIOR ASSISTANT MEDICAL OFFICER, THE COLNTY MENTAI HOSPITAL, UPTON, CHESTER

The usual "foreign body cases " are either hysterical or suicidal, and it is of interest that the patient whose history is given below swallowed the articles in response to the delusion that his stomach was too smooth. Again, unlike the hysterical or suicidal case, he did not advertise the fact.

His physical condition gave little indication of the true state of affairs. After two years of almost daily vomiting, and with $3 \frac{1}{2} \mathrm{lb}$. of assorted metal in his stomach, emaciation was slight, as was the degree of anaemia.

\section{Clinical Record}

The patient, a single man aged 28 , was admitted to the County Mental Hospital, Upton, Chester, on May 24th, 1933, as a temporary patient under the Mental Treatment Act, 1930. His occupation was that of a farmer, which he followed on a smali farm.

$\mathrm{He}$ was the youngest of a family of eight-two brothers and two sisters died in infancy. Of the remaining three, one brother and one sister are married and well; the remaining sister lives with the mother on the farm, and is well. The father died twenty-four years ago of " cancer of the stomach." The only definite psychopathic heredity was found on this side. Two cousins of the father (the patient's second cousins), a brother and sister, committed suicide by shooting about twenty years ago. Two other second cousins (males) of the patient have been patients here, one of them on two occasions. Both presented exactly the same psychosis-that of recurrent melancholia-and both are at present well.

The patient, after leaving school, where he had been a very poor scholar, started work on his mother's farm. For the last four years he was very lazy and sulky, and did very little work. . Two years ago he started vomiting, and had done so after almost every meal since. He was always thirsty, and often drank vinegar; he was also fond of drinking a decoction of dandelion leaves.

After the diagnosis of his gastric trouble was complete, the mother and sister were interviewed at the hospital. Both were found to be very emotional, and could give only a very garbled history. They had considered the possibility of the patient having swallowed things, as they had missed many forks and spoons and various articles about the house, but he always denied it. They first started missing the articles about a year prior to his admission here.

On admission the patient was dull, lethargic, and disinterested. Five days later he had not changed. $\mathrm{He}$ was totally disorientated in time, place, and person. $\mathrm{He}$ answered questions in a monosyllabic manner, and was obviously indulging in fantasy. It was almost impossible to approach him in the sphere of reality.

He stated on being questioned, that he was in the police station, and that I (the examiner) was a landowner. After, he was made with difficulty to understand that he was in hospital, and, pressed for a reason for this, said, "Well, my stomach is too smooth." This statement was followed by inquiries as to what he had done about this, and if he had swallowed rough things. $\mathrm{He}$ denied swallowing anything but food, and would say nothing further. On subsequent examinations the result was the same; he did not even repeat that his stomach was too smooth. His habits were utterly degraded. Masturbation was frequent and open. Most of the day he was content to lie under the bedclothes. He sometimes gazed round the room smiling foolishly, and appeared to have auditory hallucinations. He was diagnosed as an advanced schizophrenic. 